\title{
Stock Origins of Subadult and Adult Atlantic Sturgeon, Acipenser oxyrinchus, in a Non-natal Estuary, Long Island Sound
}

\author{
John R. Waldman • Tim King • Tom Savoy • \\ Lorraine Maceda • Cheryl Grunwald • Isaac Wirgin
}

Received: 3 April 2012 /Revised: 30 September 2012 / Accepted: 29 October 2012 /Published online: 28 November 2012

(C) The Author(s) 2012. This article is published with open access at Springerlink.com

\begin{abstract}
The anadromous acipenserid Atlantic sturgeon Acipenser oxyrinchus was listed in 2012 under the U.S. Endangered Species Act as having four endangered and one threatened distinct population segment (DPS) in American waters. Anthropogenic activities outside of natal estuaries, particularly bycatch, may hinder the abilities of some populations to rebuild. Most Atlantic sturgeon are residential for their first 2-6 years within their natal estuaries, whereas older subadults and adults may migrate to nonnatal estuaries and coastal locations. Previous studies demonstrated that subadults and adults aggregate during summer at locations in Long Island Sound (LIS) and its tributary, the Connecticut River; however, the population origin of these fish is unknown. Because of its geographic proximity and relatively robust population, we hypothesized that the LIS and Connecticut River aggregations were almost solely derived from the Hudson River. We used microsatellite nuclear
\end{abstract}

\section{J. R. Waldman}

Biology Department, Queens College

of the City University of New York,

65-30 Kissena Boulevard,

Flushing, NY 11367-1597, USA

T. King

U.S. Geological Survey, Leetown Science Center,

11649 Leetown Road,

Kearneysville, WV 25430, USA

T. Savoy

Connecticut Department of Environmental Protection,

Marine Fisheries Division,

333 Ferry Road,

Old Lyme, CT 06371, USA

L. Maceda $\cdot$ C. Grunwald $\cdot$ I. Wirgin $(\bowtie)$

Department of Environmental Medicine,

NYU School of Medicine,

57 Old Forge Road,

Tuxedo, NY 10987, USA

e-mail: Isaac.wirgin@nyumc.org
DNA analysis at 11 loci and mitochondrial DNA control region sequence analyses to estimate the relative contributions of nine Atlantic sturgeon populations and the five DPS to these aggregations using individual-based assignment tests and mixed-stock analysis. From 64 to $73 \%$ of specimens from LIS were estimated to be of Hudson origin. Similarly, $66-76 \%$ of specimens from the Connecticut River were of Hudson origin. However, moderate numbers of specimens were detected from distant spawning populations in the southeastern DPS and from two populations once thought to be extirpated or nearly so, the James River (6-7.3\%), and the Delaware River (7.6-12\%). Additionally, specimens were detected from all five DPS in both the LIS and Connecticut River collections. These results highlight the difficulty of evaluating the status of individual Atlantic sturgeon populations because of the propensity of subadults and adults to migrate for extended duration to distant sites where they may be vulnerable to anthropogenic disturbances.

Keywords Atlantic sturgeon - Anadromous · Estuary · Mitochondrial DNA $\cdot$ Microsatellites $\cdot$ Mixed-stock analysis

\section{Introduction}

Anadromous fishes, spawned in freshwaters, often use the estuaries associated with their natal rivers as habitats for growth and maturation as subadults. However, other estuaries that are not part of watersheds that support those same species serve as alternative estuarine habitats. Use of non-natal estuaries should provide a lessening of intraspecific competition in comparison with cohorts remaining within natal estuaries. But movement among estuaries may hold predatory exposure and bioenergetic costs. 
Atlantic sturgeon, Acipenser oxyrinchus, is an anadromous species with life history characteristics that should favor the use of non-natal estuaries. Juveniles grow quickly and subadults reach lengths of as much as $130 \mathrm{~cm}$ total length or more (Bain 1997), which could promote high levels of intraspecific competition within a natal system. Moreover, its large size and plated torso should reduce its field of predators when moving through coastal waters compared with other anadromous fishes. Finally, Atlantic sturgeon may exit natal estuaries as young as age 2 (Bain 1997), or, in rare instances, at age 1 (Savoy et al. 2011), but some females from northern populations may not mature until well into their 20s (Scott and Crossman 1973). This means that individual subadults may have almost a decade to as much as two decades with no imperative to return to their natal river and are thus free for an extended time to inhabit both coastal waters and non-natal estuaries.

Not much is known about the movements of Atlantic sturgeon in marine waters, with few individuals tagged historically because of their relative scarcity and high commercial value (Waldman et al. 1996). Dovel and Berggren (1983) showed through recapture of subadults marked in low-salinity tidal waters of the Hudson River between 1975 and 1978 that they ranged along a broad portion of the Eastern Seaboard. However, of the 60 recapture locations outside the Hudson Estuary, the great majority were from estuaries, including the Delaware and Chesapeake systems. Additionally, only two originated from outside the Virginian Zoogeographic Province (that includes the Hudson), from Massachusetts Bay, and from the ocean south of Cape Hatteras. Review of survey data by Dunton et al. (2010) indicated that Atlantic sturgeon in coastal waters utilize mainly shallow migration corridors $(<20 \mathrm{~m})$.

Atlantic sturgeon were fished so heavily in estuaries such as the Delaware Bay in the 1890s that some populations crashed to extirpation or relict sizes (Secor and Waldman 1999). Other fisheries persisted at low levels through much of the twentieth century, including in the Hudson River and New York Bight. But sharply increased landings of spawners in the Hudson and subadults in the New York Bight were among the reasons for the institution of a federal moratorium on Atlantic sturgeon harvest in US waters in 1998 that could last as long as 40 years. In 1993 and 1994, near the end of these New York fisheries, Waldman et al. (1996) analyzed 112 subadult Atlantic sturgeon from the New York Bight collected along both the New Jersey and southern Long Island coastlines. Using genetic mixed-stock analysis based on mitochondrial DNA (mtDNA) restriction fragment length polymorphism analysis, they estimated $99.1 \%$ Hudson River, $0.9 \%$ southeastern stock, and $0.0 \%$ Canadian stock contributions to this coastal collection (with the preferred unconditional estimate; Xu et al. 1994). More recently, using mtDNA control region sequencing data only and reference population data from Grunwald et al. (2008), Dunton et al. (2011) estimated a lower Hudson contribution than Waldman et al. (1996) for the sturgeon collected from 2005-2009 in the New York Bight, of $70.3 \%$.

Long Island Sound (LIS) estuary runs roughly southwest-northeast, is approximately 110 miles long and 21 miles in width at its widest point, and is 337,000 ha in area. LIS lies between Connecticut and the north coast of Long Island, New York, is proximal to the Hudson River, and receives its greatest freshwater input from the Connecticut River. The East River provides a direct conduit between the Hudson River and LIS, but it is not known whether this is a major movement corridor for Atlantic sturgeon. Although the Connecticut River has higher freshwater runoff than the Hudson, it has a short tidal reach and does not currently appear to support reproduction by Atlantic sturgeon (Atlantic Sturgeon Status Review Team 2007). Nonetheless, its lowest reaches do host aggregations of subadult Atlantic sturgeon, as do a few selected areas in LIS in its Central Basin and offshore of the Connecticut River's mouth (Savoy and Pacileo 2003). From 1984 to 2000, 444 Atlantic sturgeon were collected at these sites. Savoy and Pacileo (2003) hypothesized that these sturgeon originated from the Hudson, but no genetic analysis was performed on them. Of these captured sturgeon, 333 were marked with external tags, with 13 recaptures through 1999 emanating from between New Hampshire and Maryland, but with most $(N=4)$ from LIS.

Since the coastwide Atlantic sturgeon harvest moratorium was instituted in 1998, there have been indications of partial recoveries for some populations and others that were found to be more robust than assumed (Wirgin et al. 2007). Notable was the first finding of numerous young-of-the-year specimens in the Delaware River in 2009 (Fisher 2009), proof that successful natural reproduction had occurred there. Similarly, the population of the James River, VA, was believed with up to $99 \%$ probability to be extirpated (Grogan and Boreman 1998), but may have recently rebounded to more viable levels (Balazik et al. 2012). However, Atlantic sturgeon was listed in April 2012 for protection under the U.S. Endangered Species Act (ESA) as five distinct population segments (DPS). Four of the DPS (New York Bight, Chesapeake Bay, Carolina, and Southeastern) have been afforded endangered status, while the fifth in the Gulf of Maine has been designated as threatened. DPSs are predicated on geographic clusters of their spawning rivers, not on their ranges in coastal waters which remain poorly known and where they are subject as mixed assemblages to bycatch fisheries (Stein et al. 2004). Determination of the population or DPS origin of individuals in coastal aggregations such as LIS was identified as a high-priority research objective in the recent recommendation to list Atlantic sturgeon under the ESA (Federal Register 2012). 
Atlantic sturgeon subadults have continued to be surveyed and tissue samples have been collected from the lower Connecticut River and two LIS sites. Although Waldman et al. (1996) detected an almost $100 \%$ Hudson contribution to the targeted fishery in the New York Bight and Savoy and Pacileo (2003) believed that LIS specimens likely were from the Hudson, Waldman and Wirgin (1998) identified about two dozen rivers on the Eastern Seaboard that once had or still have spawning populations of Atlantic sturgeon and that could serve as sources for these LIS aggregations. We hypothesized that these LIS aggregations would demonstrate an overwhelming contribution from the Hudson River given its proximity and relatively robust abundance. Alternatively, the Hudson might make a more modest contribution given the many potential contributing populations, indications of some partial population recoveries, evidence that some individuals do not respect zoogeographic boundaries, and with LIS being near the center of the species coastal range and thus likely to see individuals from both the north and south. We used analysis of mtDNA control region sequence haplotypes and nDNA microsatellite frequencies at 11 loci to test this notion and also to provide new information potentially germane to the conservation status of individual DPS.

\section{Materials and Methods}

\section{Sample Collections}

Directed efforts by the Connecticut Department of Environmental Protection captured Atlantic sturgeon in Connecticut waters of LIS and the lower Connecticut River (Fig. 1). Skiff trawls (10-m headrope, 5.9-cm mesh) were employed in the Connecticut River (lower $15 \mathrm{~km}$ ) and in the shallower areas around its mouth in LIS. The trawl was towed with a 5.2-m boat at approximately 2.5 knots over the ground for $10 \mathrm{~min}$. The majority of sturgeon in LIS was captured with

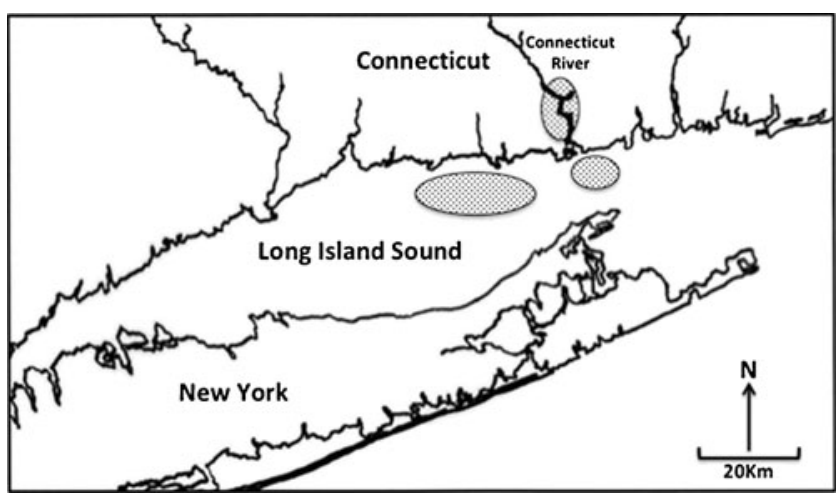

Fig. 1 Map of the central Long Island Sound depicting two sampling locations within Long Island Sound proper and the lower Connecticut River where mixed aggregations of subadult and adult Atlantic sturgeon were collected for this study anchored gill nets (10.0- to 20.3-cm stretched mesh in 2.5$\mathrm{cm}$ increments). Gillnets (multifilament mesh, $100 \mathrm{~m}$ long by $2.5 \mathrm{~m}$ deep, one mesh size per net) were anchored, leadline to contact substrate, parallel to the major flow for up to $4 \mathrm{~h}$. All Atlantic sturgeon collected were measured (total length, TL, in millimeters). Samples from LIS were collected in $2006(n=21), 2007(n=42), 2008(n=123)$, and $2009(n=90)$. Samples from the Connecticut River were collected in 1989-1991 $(n=15), 2005(n=6), 2007(n=5)$, $2008(n=6), 2009(n=14), 2010(n=42)$, and $2011(n=35)$. Seasonally, the earliest samples from both locales were collected in mid-May and the latest in late October. A 1$\mathrm{cm}^{2}$ square piece of anal fin tissue was removed from all specimens with surgical scissors and placed into individually labeled vials with $95 \%$ ethanol.

\section{DNA Isolations}

Total DNA was isolated from fin clips that were initially washed with PBS, incubated in CTAB buffer (Saghai-Maroof et al. 1984), and digested with proteinase $\mathrm{K}$ at $65^{\circ} \mathrm{C}$, followed by standard phenol-chloroform extractions and alcohol precipitations. DNA concentrations and purities were evaluated using a Nanodrop ND-1000 Spectophotometer (NanoDrop Technologies, Wilmington, DE). The DNA concentrations of samples were adjusted to $50 \mathrm{ng} / \mu \mathrm{l}$ for the standardization of subsequent procedures.

\section{Mitochondrial DNA Control Region Sequence Analysis}

Atlantic sturgeon-specific primers S1 (5'-ACATTAAAC TATTCTCTGGC-3') and G1 (5'-GAATGATATACTGTTC TACC-3'; Ong et al. 1996) amplified an approximate 560-bp portion of the control region and were used to sequence a portion of it. We report here data on only $205 \mathrm{bp}$ of the amplicon to allow for the comparison of LIS and Connecticut River specimens of unknown origin to previously characterized reference populations (Grunwald et al. 2008).

PCR reactions were in $50-\mu \mathrm{l}$ volumes containing $5 \mu \mathrm{l}$ of $10 \times$ reaction buffer (Roche Applied Science, Indianapolis, IN), $0.25 \mu \mathrm{l}$ of each dNTP (25 mM stocks; GE Healthcare, Piscataway, NJ), $0.07 \mu$ of S1 primer, $0.05 \mu \mathrm{l}$ of G1 primer (100 $\mu \mathrm{M}$ stocks; Integrated DNA Technologies, Coralville, IA), $50 \mathrm{ng}$ of template DNA, $1 \mathrm{U}$ of Taq DNA polymerase (Roche Applied Science), and $43.9 \mu$ of $\mathrm{H}_{2} \mathrm{O}$. Amplification conditions were $94^{\circ} \mathrm{C}$ for $5 \mathrm{~min}$ followed by 40 cycles at $94^{\circ}$ $\mathrm{C}$ for $45 \mathrm{~s}, 56{ }^{\circ} \mathrm{C}$ for $45 \mathrm{~s}, 72^{\circ} \mathrm{C}$ for $60 \mathrm{~s}$, followed by a final extension at $72{ }^{\circ} \mathrm{C}$ for $10 \mathrm{~min}$ in MJ Research PTC- $100^{\mathrm{TM}}$ thermal cyclers. PCR amplicons were purified with QIAquick PCR Purification kits (Qiagen, Valencia, CA).

Purified PCR products were Dye Terminator Cycle Sequenced as described by the manufacturer (Beckman Coulter, Inc., Fullerton, CA). Sequencing conditions were 30 cycles at 
$96{ }^{\circ} \mathrm{C}$ for $20 \mathrm{~s}, 50{ }^{\circ} \mathrm{C}$ for $20 \mathrm{~s}$, and $60^{\circ} \mathrm{C}$ for $4 \mathrm{~min}$. Sequencing products were EtOH-precipitated as recommended by Beckman Coulter (except no EDTA was added), resuspended in $40 \mu \mathrm{l}$ of Beckman Coulter CEQ sample loading buffer, loaded into a Beckman Coulter $\mathrm{CEQ}^{\mathrm{TM}} 8000$ automated capillary-based DNA sequencer, run using the standard long fast read method (LFR-1), and analyzed with the Sequence Analysis Module of the $\mathrm{CEQ}^{\mathrm{TM}} 8000$ Genetic Analysis System.

\section{Microsatellite Analysis}

Eleven informative microsatellite loci were scored in specimens from the LIS and Connecticut River. These included LS19, LS39, LS54, LS68 (May et al. 1997), Aox23, AoxD45 (King et al. 2001), Aox44, AoxD165, AoxD170, AoxD188, and AoxD24 (Henderson-Arzapalo and King 2002). These loci were selected because they could be reliably scored, are unlinked, and in previous studies were effective in distinguishing reference fish from spawning populations (King et al. 2001, unpublished data).

PCR reactions were in $12.5-\mu 1$ total volumes containing $1.25 \mu \mathrm{l}$ of $10 \times$ reaction buffer (KlenTaq1, Ab Peptides, Inc., St. Louis, MO), $0.1 \mu \mathrm{l}$ of each dNTP (25 mM stocks; GE Healthcare), $0.5 \mu \mathrm{l}$ of a $1-\mu \mathrm{M}$ stock of each primer one of which was labeled with Beckman Coulter dyes D4-PA or D3PA (Sigma, St. Louis, MO), $0.025 \mu l$ of KlenTaq1 enzyme (25 U/ $\mu \mathrm{l}$; Ab Peptides), $3.5 \mu \mathrm{l}$ of $25 \mathrm{ng} / \mu \mathrm{l}$ of genomic DNA, and $6.63 \mu \mathrm{l}$ of $\mathrm{H}_{2} \mathrm{O}$. Amplification conditions were $95^{\circ} \mathrm{C}$ for 5 min followed by 65 cycles at $95{ }^{\circ} \mathrm{C}$ for $30 \mathrm{~s}, 60$ or $64{ }^{\circ} \mathrm{C}$ (Aox 23 and Aox 45 only) for $30 \mathrm{~s}, 72^{\circ} \mathrm{C}$ for $60 \mathrm{~s}$, followed by a final extension at $72{ }^{\circ} \mathrm{C}$ for $7 \mathrm{~min}$ in MJ Research PTC-100 thermal cyclers.

Characterization of microsatellite genotypes was performed using a Beckman Coulter $\mathrm{CEQ}^{\mathrm{TM}} 8000$ capillarybased DNA sequencer (Beckman Coulter). PCR reactions were multi-pooled and $0.5-3 \mu \mathrm{l}$ of each reaction was added to $33 \mu \mathrm{l}$ of a mixture of A.C.E. formamide $(1,000 \mu \mathrm{l}$; Amresco, Solon, $\mathrm{OH}$ ) and CEQ DNA Size Standard-400 (9 $\mathrm{\mu l}$; Beckman Coulter). Reactions were loaded onto 96well plates and run with the FRAG 1 program (Beckman Coulter). MICRO-CHECKER software (Oosterhout et al. 2004) was used to test for the presence of null alleles, errors due to microsatellite stuttering, and large-allele dropout.

\section{Statistical Analysis}

Reference genetic data were obtained from spawning adults $(\mathrm{TL} \geq 130 \mathrm{~cm})$ or juveniles $(\mathrm{TL} \leq 50 \mathrm{~cm})$ collected from nine spawning rivers (Fig. 2). Only specimens of these lengths were included in reference collections to help ensure that they were natal to the rivers in which they were collected. Mitochondrial DNA control region sequence haplotype data for these reference collections were reported in Grunwald et al. (2008) and microsatellite results in King et al. (2001, unpublished data). The baseline dataset consisted of multi-locus genotypes for 427 specimens genotyped at 11 microsatellite loci and mtDNA control region sequence haplotypes coded as a homozygous diploid locus (e.g., haplotype A, 001001). Analyses were performed to provide estimates of accuracy of identification of individuals to these nine populations and the five DPS in the U.S. ESA listing and the Saint John River, Canada.

Individual-based assignment (IBA) tests and mixed-stock analysis (MSA) were used to estimate the stock origin of Atlantic sturgeon in the fisheries independent surveys in LIS and the Connecticut River. Individual-based assignment tests using multi-locus likelihood functions (after Paetkau et al. 1995) were used to determine the likelihood of each individual's genotype being found in the collection from which it was sampled (without replacement) using the program GeneClass2 (Cornuet et al. 1999). The analysis determines the likelihood ratio assuming the gene pool is in Hardy-Weinberg equilibrium with frequencies as specified in the collection. In the event of null frequencies, a constant likelihood of 0.01 was assumed.

MSA was also used to estimate the proportion of each baseline population in the mixed samples of unknown origin in LIS and the Connecticut River and to determine the probability of each individual belonging to each of the baseline stocks. In contrast to individual assignment, MSA applies mixture modelling, taking into account the genotypes of individual fish across multiple loci, the multi-locus genotype distributions of the baseline samples, and, in addition, the multi-locus genotype distribution in the mixture sample. We used ONCOR (Kalinowski 2008) and the same reference dataset used for the IBA to perform the MSA. We estimated mixture proportions with $95 \%$ conference limits based on 10,000 bootstraps. Results were reported for each population in the baseline as well as for each DPS.

Temporal inter-annual stability of genotypes across years of collection and intra-annual stability within years of collection in the LIS and the Connecticut River collections were evaluated using pairwise allelic differentiation tests in GENEPOP, version 4.0.10, using default Markov chain parameters (Rousset 2007). Allelic differentiation tests were also used to evaluate genetic similarity between larger and smaller specimens collected from both the LIS and Connecticut River. For both collections, we compared allelic frequencies in specimens smaller and larger than $100-\mathrm{cm}$ TL as well as above and below the sample median total lengths of $121.5 \mathrm{~cm}$ in LIS and $91.0 \mathrm{~cm}$ in the Connecticut River. Only the microsatellite data were used for these comparisons. The total lengths of specimens assigned to different source populations in LIS and the Connecticut River were initially compared using one-way analysis of variance in StatPlus:mac LE.2009 followed by Dunnett's post hoc test. 
Fig. 2 Map of the Atlantic coast of North America depicting where nine spawning river collections of juvenile $(\mathrm{TL} \leq 50 \mathrm{~cm})$ and adult $(\mathrm{TL} \geq$ $130 \mathrm{~cm}$ ) Atlantic sturgeon used as the references in this study were made

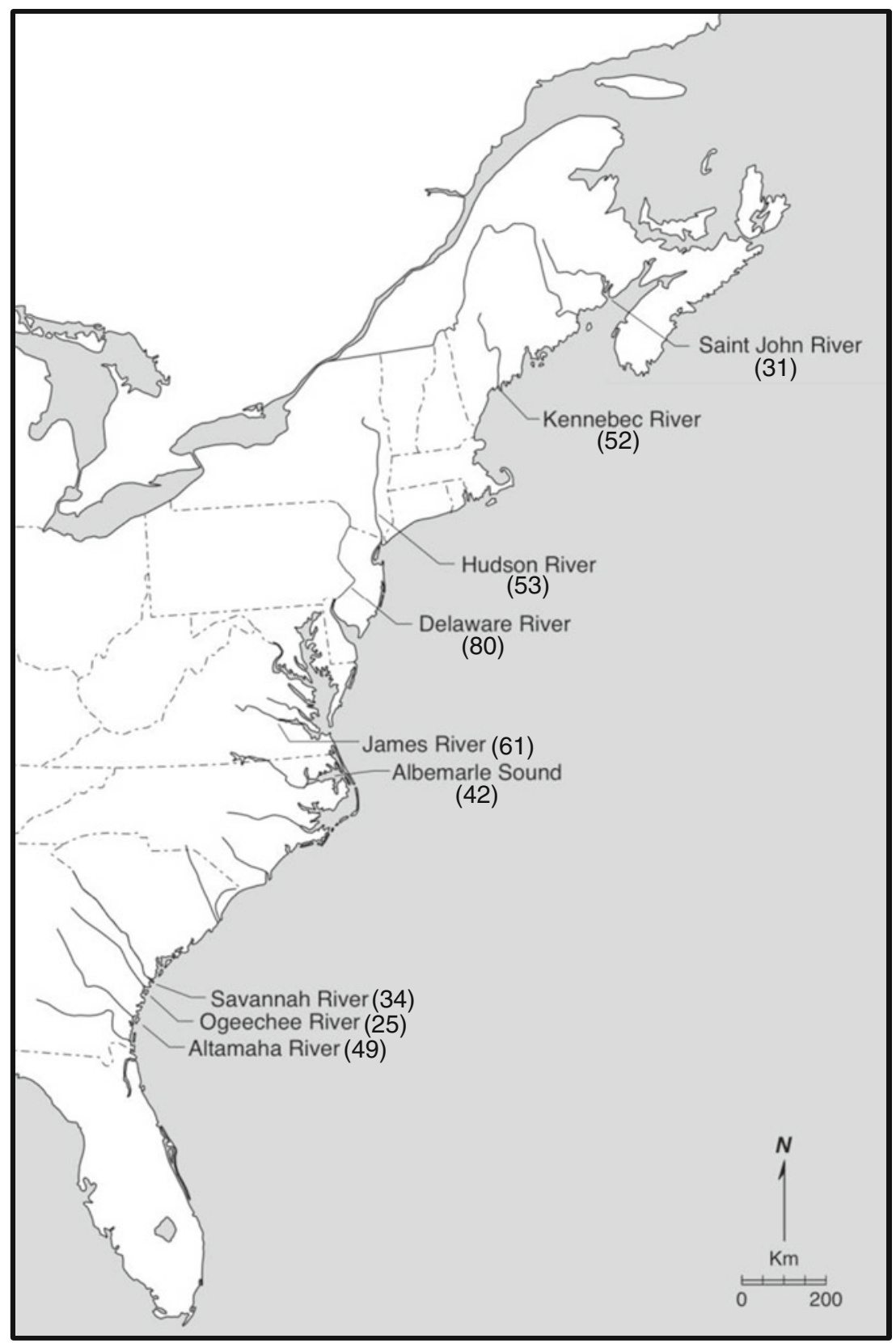

\section{Results}

\section{Overall Summary}

In total, 124 Atlantic sturgeon specimens were genetically characterized from the Connecticut River, with a mean length of 936.9-mm TL $( \pm 153.3)$. Another 275 Atlantic sturgeon specimens were genetically characterized from LIS, with a mean length of 123.8 -cm TL $( \pm 220)$. The mean length of our collection from LIS was significantly greater than that from the Connecticut River $(p<0.0001)$. Allelic differentiation between our total LIS and total Connecticut River collections was also significant using Fisher's exact test $\left(\chi^{2}=36.1, p=0.03\right)$, suggesting that aggregations at these two locales had heterogeneous origins.

Hardy-Weinberg analyses of microsatellite DNA genotypes for the LIS and Connecticut River collections indicated disequilibria for both; Connecticut River $\left(\chi^{2}=\right.$ infinity, $p=$ highly significant) and LIS ( $\chi^{2}=$ infinity, $p=$ highly significant), suggesting that these samples comprised specimens from more than one spawning population. In both, there was a significant deficit of heterozygotes. Furthermore, the mean $F_{\text {is }}$ values for the LIS and Connecticut River collections were 0.0152 and 0.0578 , respectively. Our previous characterizations of these loci in samples from the nine reference populations showed Hardy-Weinberg equilibrium for each. Our earlier studies also 
revealed significant mtDNA control region haplotype and microsatellite DNA allelic frequency differences $(p<0.05)$ among all nine reference (Fig. 2) and five DPS collections (Fig. 3; Grunwald et al. 2008; King et al. 2001, unpublished data). Thus, there appeared to be sufficient differentiation among them to conduct mixed-stock analysis on the aggregations found in LIS and its Connecticut River tributary.

Accuracy in assigning individual reference specimens to the DPS from which they were collected based on the combination of 11 microsatellite loci and mtDNA control region sequence was high (mean $=96.5 \%$; Fig. 3b). Only specimens from the Carolina DPS were not assigned with greater than $95 \%$ accuracy to their DPS of collection (88.1\%), and in this case, all incorrect assignments were to the neighboring Southeastern DPS. Assignment accuracies to individual populations were lower, with a mean value of $84.5 \%$. Lowest accuracies (56$81.6 \%$ ) were to those populations within the Southeastern DPS, consistent with earlier mtDNA (Wirgin et al. 2000; Grunwald et al. 2008) and microsatellite (King et al. 2001, unpublished data) studies comparing these and other populations within that area.

We also compared assignment accuracies to the nine reference populations and five DPS using the 11 microsatellite loci alone, mtDNA control region haplotypes alone, and the combination of the 11 microsatellite loci and mtDNA control region haplotypes (Table 1). As expected, the combination of microsatellite and mtDNA data provided the highest accuracy in assigning specimens to the populations or DPS from which they were collected. In comparison, the use of mtDNA control region haplotypes alone performed poorly in assigning ancestry, with only $39.8 \%$ of specimens assigned to the reference river from which they were collected and $64.9 \%$ assigned to the correct DPS. This is probably due to the high percentage of specimens with the mtDNA A haplotype which is common to all nine reference populations ( $40.9 \pm 32.2 \%$; Grunwald et al. 2008; Wirgin et al., unpublished data). The inaccuracy of assignments based on mtDNA haplotype data alone will be particularly pronounced for those populations with high frequencies of this haplotype such as the Saint John (100\%), Kennebec (83.6\%), and Albermarle Sound $(55.3 \%)$.

\section{Origin of the Connecticut River Collection}

Based on results from IBA tests, the Hudson River was the major but not the only contributor to the mixed aggregation

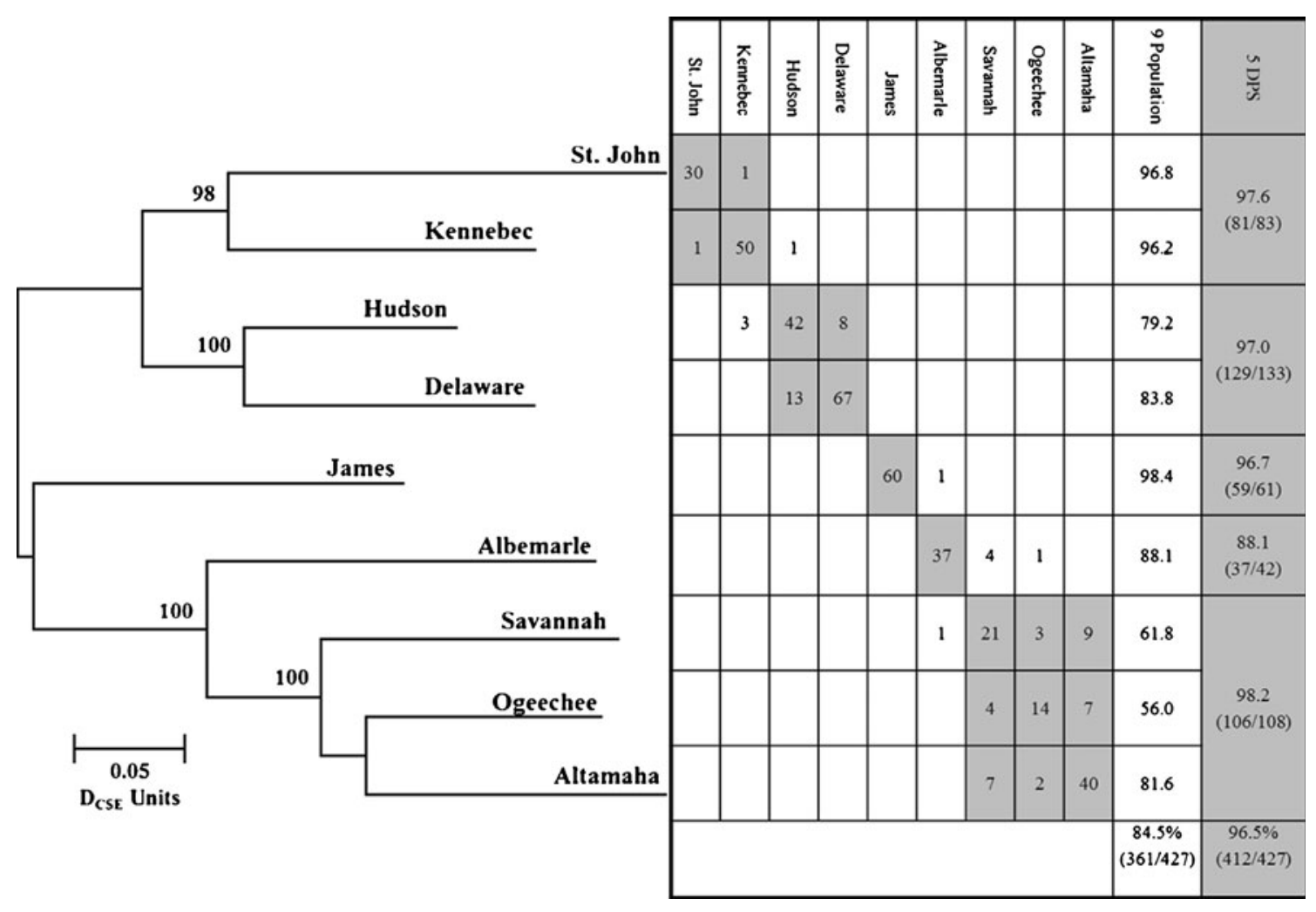

Fig. 3 a Neighbor-joining tree depicting evolutionary relationships (as the Cavalli-Sforza and Edwards chord distances) among nine Atlantic sturgeon reference spawning populations that were surveyed at 11 microsatellite loci (King et al. 2012). Numbers represent bootstrap support at each branch with 5,000 replicates of resampling across loci (Henderson-Arzapalo and King 2002). b Results of assignment testing using 11 microsatellite DNA loci and mitochondrial DNA control region haplotypes (scored as a homozygous locus) to determine the likelihood of each individual's multi-locus genotype/haplotype being found in the reference collection and distinct population segment from which it was collected (without replacement) using the program GeneClass2 
Table 1 Assignment accuracies (in percent) and numbers of 427 Atlantic sturgeon specimens assigned correctly to the nine reference populations or five DPS from which they were collected using individual-based assignment tests with a combination of data from 11 microsatellite loci and mtDNA control region haplotypes, data from 11 microsatellite loci alone, or mtDNA control sequence haplotype data alone

\begin{tabular}{lccc}
\hline Model & nDNA+mtDNA & nDNA & mtDNA \\
\hline Nine populations & $84.1 \%$ & $80.6 \%$ & $39.8 \%$ \\
& $(359 / 427)$ & $(344 / 427)$ & $(170 / 427)$ \\
Five DPS & $94.6 \%$ & $93.7 \%$ & $64.9 \%$ \\
& $(404 / 427)$ & $(400 / 427)$ & $(277 / 427)$ \\
\hline
\end{tabular}

in the lower Connecticut River. Approximately $66 \%$ of specimens collected in the Connecticut River were of Hudson River origin (Table 2). However, seven other rivers and all five DPS contributed to this collection, including the Saint John (3.2\%) in Canada, Kennebec (9.7\%) in the Gulf of Maine, the Delaware (8.1\%) in the New York Bight DPS, the James (4.8\%) in the Chesapeake DPS, Albermarle Sound $(0.8 \%)$ in the Carolina DPS, and the Savannah $(6.5 \%)$ and Altamaha $(0.8 \%)$ in the Southeastern DPS. Results from mixed-stock analysis were similar, but showed a somewhat increased Hudson River contribution (75.6 \%) and proportionally lesser contributions from the other five rivers (Table 2 ).

We also analyzed temporal stability among years of collection and among months of collection in the Connecticut River. Interestingly, there was a highly significant difference in microsatellite allelic frequencies among years of collection $\left(\chi^{2}=59.3, p<0.001\right)$, with the greatest difference between samples collected from 1989-1991 compared to those collected in 2010 or 2011 . However, there was no significant allelic $\left(\chi^{2}=18.71, p=0.663\right)$ differentiation among samples collected in early summer (June-July) compared to those collected later in summer (August-September).

\section{Origin of the Long Island Sound Collection}

Results from IBA tests indicated that all reference populations except that in the Altamaha River contributed to the LIS mixed assemblage (Table 3). Once again, the Hudson River contribution predominated (64\%). Other major contributors in descending order included the Delaware River (12\%), James River (7.3\%), Ogeechee River (5.1\%), Kennebec River (5\%), Albermarle Sound (3.3\%), and Savannah River (2.9\%). Mixed-stock analysis provided similar results with a somewhat greater Hudson River contribution $(72.8 \%)$, followed by the Delaware River $(7.6 \%)$, James River (6.0\%), and Ogeechee River (5.1\%; Table 3).

We also evaluated the temporal stability of microsatellite allelic frequencies among years of collection and among months of collection in LIS. In contrast to the Connecticut
River results, we found homogeneity of allelic frequencies among LIS samples collected across 4 years: 2006, 2007, 2008, and $2009\left(\chi^{2}=18.46, p=0.678\right)$. We also compared collections from LIS made in June-July, August-September, and October across the 4 years and found no evidence of intra-annual temporal instability $\left(\chi^{2}=18.32, p=0.686\right)$.

\section{Comparison of Allelic Frequencies Between Larger and Smaller Specimens}

The question remained as to why the Hudson River was the primary contributor to both the Connecticut River and LIS collections. It is possible that the Hudson River was the primary contributor because of the relatively robust size of its contemporary population or because the migratory ability of Atlantic sturgeon, i.e., distance traveled, is directly related to their size. To address this latter possibility, we compared the allelic frequencies between LIS specimens that were longer and smaller than 121.2-cm TL (median length of specimens in the LIS collection). We found a strong genetic difference between smaller and larger individuals from the LIS collection $\left(\chi^{2}=48.97, p<0.001\right)$, suggesting that their stock origins differed significantly. We also compared allelic frequencies between specimens $\geq 91.0-\mathrm{cm} \mathrm{TL}$ (median length of specimens in the Connecticut River collection) and those that were $\leq 91.0-\mathrm{cm}$ TL from the Connecticut River and found a highly significant difference in allelic frequencies between the two size groups $\left(\chi^{2}=42.1\right.$, $p=0.006)$.

We also compared the total lengths of LIS specimens assigned to each of the source populations using ANOVA. We found highly significant differences among sources in total length of specimens $(p<0.001, d f=7)$, but using the Dunnett's post hoc test, the Hudson River-assigned specimens in our Connecticut River collections did not differ significantly in total length compared to specimens from other sources. Thus, specimens of Hudson River ancestry in our collection were not significantly smaller than those assigned to other source populations. In comparison, using ANOVA, Connecticut River specimens from different source populations did not exhibit significant difference in their total lengths. In summary, contrary to our expectation, neither specimens from the Connecticut River nor the LIS collections that were assigned a Hudson River ancestry were smaller than specimens that assigned to other more distant sources.

\section{Discussion}

The results confirmed our expectation of a dominant Hudson River contribution to the aggregations of subadult and adult Atlantic sturgeon in the LIS and its Connecticut River 
Table 2 Individual-based assignment test (numbers and percent classified) and mixed-stock analysis results for Connecticut River collections of Atlantic sturgeon to five DPS or nine populations
Individual assignment results calculated in GeneClass2 were based on nDNA (11 microsatellites) and mtDNA control region results combined, nDNA results alone (11 microsatellites), or mtDNA results alone. Mixedstock results calculated in ONCOR were based on the combination of nDNA (11 microsatellites) and mtDNA results

\begin{tabular}{lllll}
\hline & \multicolumn{2}{l}{ Individual-based assignment tests } & & \multirow{2}{*}{ Mixed-stock analysis } \\
\cline { 2 - 3 } & nDNA and mtDNA (\%) & nDNA alone (\%) & mtDNA alone & nDNA and mtDNA \\
\hline Five distinct population segments & & & \\
Gulf of Maine & $18(14.5)$ & $18(14.5)$ & $28(22.6)$ & $0.1195(0.059-0.196)$ \\
New York Bight & $86(69.3)$ & $83(66.9)$ & $75(60.5)$ & $0.7441(0.646-0.822)$ \\
Chesapeake Bay & $9(7.3)$ & $12(9.7)$ & $10(8.0)$ & $0.0543(0.017-0.103)$ \\
Carolina & $2(1.6)$ & $1(0.8)$ & $9(7.3)$ & $0.0122(0.000-0.039)$ \\
Southeastern & $9(7.3)$ & $10(8.1)$ & $2(1.6)$ & $0.0699(0.029-0.127)$ \\
Total & $124(100.0)$ & $124(100.0)$ & $124(100.0)$ & \\
Nine populations & & & & \\
Saint John & $4(3.2)$ & $6(4.8)$ & $26(21.0)$ & $0.0228(0.000-0.056)$ \\
Kennebec & $12(9.7)$ & $12(9.7)$ & $1(0.8)$ & $0.0717(0.022-0.139)$ \\
Hudson & $82(66.1)$ & $78(62.8)$ & $75(60.5)$ & $0.7555(0.602-0.827)$ \\
Delaware & $10(8.1)$ & $9(7.3)$ & $8(6.5)$ & $0.0206(0.000-0.146)$ \\
James & $6(4.8)$ & $8(6.5)$ & $2(1.6)$ & $0.0483(0.014-0.090)$ \\
Albemarle & $1(0.8)$ & $0(0.0)$ & $2(1.6)$ & $0.0000(0.000-0.026)$ \\
Savannah & $8(6.5)$ & $8(6.5)$ & $2(1.6)$ & $0.0810(0.011-0.121)$ \\
Ogeechee & $0(0.0)$ & $1(0.8)$ & $8(6.4)$ & $0.0000(0.000-0.033)$ \\
Altamaha & $1(0.8)$ & $2(1.6)$ & $0(0)$ & $0.0000(0.000-0.057)$ \\
Total & $124(100.0)$ & $124(100.0)$ & $124(100.0)$ & 1.000 \\
\hline & & & & \\
\hline
\end{tabular}

tributary. However, the presence there of migrants from many distant populations was unexpected. For both collections, this included representatives from all five DPS and almost all reference populations. The presence of specimens from these disparate populations indicates that subadult and adult Atlantic sturgeon appear to use coastal waters broadly, a finding definitively shown previously only for the Hudson River population (Dovel and Berggren 1983). That the Hudson River contribution was dominant could be due to the river's
Table 3 Individual-based assignment test (numbers and percent classified) and mixed-stock analysis results for Long Island Sound collections of Atlantic sturgeon to five DPS and nine spawning populations

Individual assignment test results calculated in GeneClass2 are based on nDNA (11 microsatellites) and mtDNA control region results combined, $\mathrm{nDNA}$ results alone (11 microsatellites), or mtDNA results alone. Mixedstock analysis results $(95 \%$ confidence intervals) calculated in ONCOR are based on the combination of nDNA (11 microsatellites) and mtDNA results

\begin{tabular}{lllll}
\hline & \multicolumn{2}{l}{ Individual-based assignment tests } & \multirow{2}{*}{ Mixed-stock analysis } \\
\cline { 2 - 3 } & nDNA and mtDNA (\%) & nDNA alone (\%) & mtDNA alone & nDNA and mtDNA \\
\hline Five distinct population segments & & & \\
Gulf of Maine & $25(9.1)$ & $37(13.5)$ & & $0.0628(0.028-0.109)$ \\
New York Bight & $197(71.6)$ & $184(66.8)$ & & $0.7574(0.699-0.816)$ \\
Chesapeake Bay & $22(8.0)$ & $28(10.2)$ & & $0.0721(0.040-0.109)$ \\
Carolina & $10(3.7)$ & $9(3.3)$ & & $0.0303(0.009-0.063)$ \\
Southeastern & $21(7.6)$ & $17(6.2)$ & & $0.0775(0.040-0.107)$ \\
Total & $275(100.0)$ & $275(100.0)$ & $275(100.0)$ & 1.0000 \\
Nine populations & & & & \\
Saint John & $1(0.4)$ & $5(1.8)$ & $63(23.0)$ & $0.0036(0.000-0.016)$ \\
Kennebec & $14(5.0)$ & $23(8.4)$ & $0(0.0)$ & $0.0254(0.006-0.074)$ \\
Hudson & $176(64.0)$ & $164(59.6)$ & $138(50.4)$ & $0.7281(0.589-0.773)$ \\
Delaware & $33(12.0)$ & $31(11.3)$ & $15(5.5)$ & $0.0762(0.048-0.185)$ \\
James & $20(7.3)$ & $26(9.5)$ & $16(5.8)$ & $0.0604(0.035-0.103)$ \\
Albemarle & $9(3.3)$ & $4(1.5)$ & $9(3.3)$ & $0.0239(0.004-0.050)$ \\
Savannah & $8(2.9)$ & $9(3.3)$ & $3(1.1)$ & $0.0310(0.004-0.061)$ \\
Ogeechee & $14(5.1)$ & $13(4.7)$ & $29(10.6)$ & $0.0513(0.020-0.080)$ \\
Altamaha & $0(0.0)$ & $0(0.0)$ & $1(0.3)$ & $0.0000(0.000-0.004)$ \\
Total & $275(100.0)$ & $275(100.0)$ & $274(100.0)$ & 1.0000 \\
\hline & & & &
\end{tabular}


geographic proximity, its relatively large Atlantic sturgeon population, or both.

We attempted to determine whether the predominant Hudson River contribution was due to the river's proximity to these LIS sites by comparing the size of specimens assigned Hudson River origin to those assigned to other sources. We hypothesized that smaller individuals were less likely to undergo distant coastal migrations than larger fish. As a result, we projected that specimens assigned Hudson River origin would be smaller than those assigned to other sources. However, that was not the case as there was no significant difference in the total length of specimens assigned among the nine reference populations. Thus, it remains to be determined why the Hudson River contribution predominated in the LIS mixed aggregations.

On a population-specific basis, the broad representations we found in our LIS and Connecticut River collections were minimum estimates of the number of populations that occur there because not all possible reference populations were included. For the smaller Connecticut River collection $(N=$ 124), either individuals were detected from or a non-zero mixed-stock contribution estimate of eight of the nine reference populations were made. Although their proportions of the total were low, our data suggest that specimens reached the Connecticut River from as far north as the Saint John River and as far south as the Altamaha River. For the larger $(N=275)$ LIS collection, IBA tests showed eight of nine source populations detected (none from the Altamaha River), and mixed-stock analysis showed the same eight with a possibility of a minor Altamaha contribution. These populations included representatives from two thought to be at, or near extirpation, in the recent past, the James River (Grogan and Boreman 1998) and the Delaware River (ASSRT 2007). The presence of migrants from these systems in moderate numbers in our collections suggests that these populations may be rebuilding in recent years or may not have been as depleted to as low levels as originally thought.

However, a caveat to our accuracy in assigning specimens to the Delaware River reference population should be considered. Missassignment of James River-collected reference specimens to other rivers was very low $(<2 \%$; Fig. 3$)$; thus, we are confident that our assignments of LIS or Connecticut River-collected specimens to the James River were accurate. However, missassignment of Hudson Rivercollected reference fish to the Delaware was substantial, 8 of 53 specimens $(15 \%)$; thus, it is possible that our estimate of the Delaware River contribution to the total LIS collections (10.7\% based on IBA) may be overestimated. But the presence of specimens of Delaware River origin in our Connecticut River and LIS collections is confirmed by the presence there of 22 specimens $(5.5 \%)$ with mtDNA haplotypes that are either unique to the Delaware coastwide $(5 \%)$ or absent in our Hudson River reference collection $(0.5 \%)$. Thus, specimens of Delaware River origin are almost certainly seasonally present in the LIS, but may occur in lower frequencies than we estimate.

The long duration of coastal movements of subadult and adult Atlantic sturgeon should be considered in evaluating the status of individual threatened spawning populations such as those in the James and Delaware rivers. It is possible that though absent in natal estuaries for many years, subadults from these populations may exist in coastal waters for extended periods of time before homing to their natal systems for spawning. Thus, this behavior may mask the rebuilding of populations heretofore thought to be extirpated based on surveys of juveniles and older adult life stages from spawning rivers.

The suitability of the DPS concept as applied to Atlantic sturgeon has been questioned (Grunwald et al. 2008), but it is and will continue to be used as a framework for federal management of Atlantic sturgeon (Federal Register 2012). Our five-DPS analyses showed strong dominance at both sites by the New York Bight DPS, with considerable contributions by the Gulf of Maine, Chesapeake Bay, and Southeast DPS and lesser contributions by the Carolina DPS. Together, these results indicate that at this one coastal region, representatives from all DPS are vulnerable to threats from anthropogenic disturbances. This also reinforces the concept that because of their highly migratory, but yet to be demarcated behavior, conservation of threatened populations of Atlantic sturgeon will require their management within both their natal estuaries and throughout their adult and subadult migratory circuits. However, the migratory circuits of specific spawning populations are largely unknown and will require additional genetic and mark recapture research in the future.

Whether taken at the individual stock or DPS levels, our results show that at mid-latitude coastal sites such as LIS, a mix of Atlantic sturgeon from a broad latitudinal range is to be expected. Differences in contributions between stocks or DPS at the two sites may reflect size and age differences expressed as differences in year class production from those rivers; differences in among-year tendencies to emigrate from those rivers; and differences in migration lengths related to age, size, or population of origin. For example, in our concurrent and ongoing analysis of the stock origin of Atlantic sturgeon bycaught and sampled in NOAA's Observer program, we find that specimens from southern populations tend to migrate greater distances than those from mid-Atlantic rivers (Wirgin 2012). Also, we believe that the allelic frequency difference that we report between our earliest collection from the Connecticut River made in 1989-1991 and more contemporary samples collected in 2010 and 2011 reflect increased successful production in more distant source populations in recent years. 
Not unexpectedly, stock contributions to the LIS and Connecticut River collections were dramatically different from those we report from the inner Bay of Fundy using the same genetic markers and reference population samples and for summers of three of the same years as collections made for this study, 2007-2009 (Wirgin et al. 2012). We found the summertime aggregations in the Bay of Fundy to be primarily supported by specimens from the proximal Saint John River, New Brunswick (61\%), and the Kennebec River, Maine (34\%), with a minor Hudson River (2 \%) and a possible tiny James River contribution. Taken together, the results from these two studies indicate that migrating Atlantic sturgeon usually respect the zoogeographic boundaries of their natal estuaries (Wirgin 2012), but on occasion cross these boundaries to more distant zoogeographic provinces, as suggested by Waldman et al. (1996). Whether this propensity is a function of the size, age, or population of origin of specimens has yet to be determined.

Waldman et al. (1996) found an overwhelming contribution by the Hudson River stock to the New York Bight fisheries (along the western Long Island, NY, and New Jersey coasts) that targeted subadult Atlantic sturgeon and operated in the early 1990s. In the present study, we found far greater diversity of stock contributions to two sites proximal to the New York Bight. Although they used mtDNA control region sequence data alone, Dunton et al. (2011) also found for their recent New York Bight sample a dominant Hudson River contribution $(70 \%)$ and smaller contributions from a number of mid-Atlantic (including the Delaware and James) and southern rivers (but none from northern rivers; whether this is real or an artifact of their reliance on a single locus with an absence of mtDNA control region variability in northern populations is unknown). Continuation of a strong Hudson River contribution together with representation from many other populations suggests a trend of increasing abundance of some stocks that are smaller than that in the Hudson. However, this comparison is confounded by the fact that Waldman et al. (1996) analyzed mtDNA only, which, as a single locus, is less accurate in source assignment as shown in this study and therefore may be less sensitive to minor stock contributions. However, the three-stock model (Northern, Hudson, Southeast) employed by Waldman et al. (1996) was a far simpler stock model than the nine-stock model examined in the present study, and yet, the estimated Hudson contribution was nearly $100 \%$.

We believe that the broader stock representation seen today results from the initial stages of population recoveries of smaller stocks that have occurred through the protection afforded by the coastwide harvest moratorium enacted in 1998. Of course, it is also possible that this contrast in stock composition between the current study and that of Dunton et al. (2011) may reflect differential migration from the
Hudson and other populations to the open ocean south shore of the Long Island and New Jersey coasts compared to the more protected estuarine waters of LIS and the lower Connecticut River. This issue could be definitively addressed by genetic mixed-stock analysis using both mtDNA and microsatellite analyses that compare a contemporary sample from the New York Bight and the archived 1993-1994 sample that we report in Waldman et al. (1996).

Why do large numbers of subadult and adult Atlantic sturgeon aggregate seasonally in LIS? It is possible that this large embayment may provide additional protection from environmental variability in comparison to open coastal environments or may have higher concentrations of preferred prey items. Aggregations of sturgeons from diverse locations in non-natal riverine estuaries and associated coastal areas just outside of the river mouths are well documented for several sturgeon species including Atlantic sturgeon (Fox et al. 2002; Edwards et al. 2007; Erickson and Hightower 2007; Dunton et al. 2010) and may provide concentrated feeding opportunities in these highly productive areas. Unfortunately, the abundance and distribution of benthic and infaunal invertebrate potential prey items are poorly described for Atlantic sturgeon in coastal waters. Documentation of relatively high feeding rates in LIS for Atlantic sturgeon (Savoy 2007) supports the likelihood that prey availability is important. Finally, it is too soon to conclude that LIS has higher concentrations of mixed stocks of Atlantic sturgeon than similar East Coast areas. It may be that many of these other locations have not been adequately sampled by directed research efforts.

Acknowledgments We acknowledge support of grant no. R/XG-20 from New York Sea Grant, the Northeast Region of NOAA Fisheries, the Molecular Facilities Core of NIEHS Center Grant ES00260, the U.S. Fish and Wildlife Service through a State Wildlife Grant to the Connecticut Department of Energy and Environmental Protection, the Connecticut Department of Energy and Environmental Protection Marine Fisheries Division, and the U.S. Geological Survey, Leetown Science Center.

Open Access This article is distributed under the terms of the Creative Commons Attribution License which permits any use, distribution, and reproduction in any medium, provided the original author(s) and the source are credited.

\section{References}

Atlantic Sturgeon Status Review Team. 2007. Status review of Atlantic sturgeon (Acipenser oxyrinchus oxyrinchus). Report to National Marine Fisheries Service, Northeast Regional Office. February 23, 2007.

Bain, M.B. 1997. Atlantic and shortnose sturgeons of the Hudson River: common and divergent life history attributes. Environmental Biology of Fishes 48: 347-358. 
Balazik, M., J. Van Eenennam, J. Mohler, and C. Woods. 2012. Evidence of fall spawning by Atlantic sturgeon in the James River, Virginia, USA. Transactions of the American Fisheries Society 141: 1465-1471.

Cornuet, J.M., S. Piry, G. Luikart, A. Estoup, and M. Solignac. 1999. New methods employing multilocus genotypes to select or exclude populations as origins of individuals. Genetics 153: 19892000.

Dovel, W.L., and T.J. Berggren. 1983. Atlantic sturgeon of the Hudson Estuary, New York. New York State Fish and Game Journal 30 (2): 140-172.

Dunton, K.J., A. Jordaan, K.A. McKown, D.O. Conover, and M.G. Frisk. 2010. Abundance and distribution of Atlantic sturgeon (Acipenser oxyrinchus) within the Northwest Atlantic Ocean, determined from five fishery-independent surveys. Fishery Bulletin 108: 450-465.

Dunton, K.J., D. Chapman, A. Jordaan, K. Feldheim, S.J. O'Leary, K.A. McKown, and M.G. Frisk. 2011. Genetic mixed-stock analysis of Atlantic sturgeon Acipenser oxyrinchus oxyrinchus in a heavily exploited marine habitat indicates the need for routine genetic monitoring. Journal of Fish Biology 80: 207-217.

Edwards, R.E., F.M. Paruka, and K.J. Sulak. 2007. New insights into marine migration and winter habitat of gulf sturgeon. American Fisheries Society Symposium 56: 183-196.

Erickson, D.L., and J.E. Hightower. 2007. Oceanic distribution and behavior of green sturgeon. American Fisheries Society Symposium 56: 197-211.

Federal Register. 2012. Endangered and threatened wildlife and plants; threatened and endangered status for distinct population segments of Atlantic sturgeon in the Northeast region. 77:5880-5912, February $6,2012$.

Fisher, M. 2009. Atlantic sturgeon progress report: State Wildlife Grant. Project T-4-1, Delaware Division of Fish and Wildlife, Smyrna, DE.

Fox, D.A., J.E. Hightower, and F.M. Parauka. 2002. Estuarine and nearshore marine habitat use by gulf sturgeon from the Choctawhatchee River system, Florida. American Fisheries Society Symposium 28: 111-126.

Grogan, C.S., and J. Boreman. 1998. Estimating the probability that historical populations of fish species are extirpated. North American Journal of Fisheries Management 18: 522-529.

Grunwald, C., L. Maceda, J. Waldman, J. Stabile, and I. Wirgin. 2008. Conservation of Atlantic sturgeon Acipenser oxyrinchus oxyrinchus: delineation of stock structure and distinct population segments. Conservation Genetics 8: 1566-1572.

Henderson-Arzapalo, A., and T.L. King. 2002. Novel microsatellite markers for Atlantic sturgeon population delineation and broodstock management. Molecular Ecology Notes 2: 437-439.

Kalinowski, S. T. 2008. ONCOR: Software for genetic stock identification. http://www.montana.edu/kalinowski/Software.htm.

King, T.L., B.A. Lubinski, and A.P. Spidle. 2001. Microsatellite DNA variation in Atlantic sturgeon (Acipenser oxyrinchus oxyrinchus) and cross-species amplification in the acipenseridae. Conservation Genetics 2: 103-119.

May, B., C.C. Krueger, and H.L. Kincaid. 1997. Genetic variation at microsatellite loci in sturgeon: primer sequence homology in Acipenser and Scaphirhynchus. Canadian Journal of Fisheries and Aquatic Sciences 54: 1542-1547.

Ong, T.-L., J. Stabile, J.R. Waldman, and I. Wirgin. 1996. Genetic divergence of Atlantic and Gulf of Mexico sturgeon based on sequence analysis of the mtDNA control region. Copeia 1996: 464 469.
Oosterhout, C.V., W.F. Hutchinson, D.P.M. Wills, and P. Shipley. 2004. Micro-Checker: software for identifying and correcting genotyping errors in microsatellite data. Molecular Ecology Notes 4: 535-538.

Paetkau, D., W. Calvert, I. Stirling, and C. Strobeck. 1995. Microsatellite analysis of population structure in Canadian polar bears. Molecular Ecology 4: 347-354.

Rousset, F. 2007. Genepop'007: a complete re-implementation of the Genepop software for Windows and Linux. Molecular Ecology Resources 8: 103-106.

Saghai-Maroof, M.A., K.M. Soliman, R.A. Jorgensen, and R.W. Allard. 1984. Ribosomal DNA spacer-length polymorphisms in barley: Mendelian inheritance, chromosomal location, and population dynamics. Proceedings of the National Academy of Sciences of the United States of America 81: 8014-8018.

Savoy, T. 2007. Prey eaten by Atlantic sturgeon in Connecticut waters. American Fisheries Society Symposium 56: 157-165.

Savoy, T., and D. Pacilieo. 2003. Movements and important habitats of subadult Atlantic sturgeon in Connecticut waters. Transactions of the American Fisheries Society 132: 1-8.

Savoy, T., J. Bowers, H. Corbett, M. Oliver, J. Madsen, D. Fox, and M. Fisher. 2011. Sturgeons in the mid-Atlantic region: a multi-state collaboration of research and conservation. Semi-annual progress report. Section 6 proactive species conservation program, award number NAIONMF4720030, $34 \mathrm{pp}$.

Secor, D.H., and J.R. Waldman. 1999. Historical abundance of Delaware Bay Atlantic sturgeon and potential rate of recovery. American Fisheries Society Symposium 23: 203-216.

Scott, W. B., and E. J. Crossman. 1973. Freshwater fishes of Canada. Fisheries Research Board of Canada Bulletin 184.

Stein, A.B., K.D. Friedland, and M. Sutherland. 2004. Atlantic sturgeon marine distribution and habitat use along the Northeastern coast of the United States. Transactions of the American Fisheries Society 133: 527-537.

Waldman, J.R., J.T. Hart, and I.I. Wirgin. 1996. Stock composition of the New York Bight Atlantic sturgeon fishery based on analysis of mitochondrial DNA. Transactions of the American Fisheries Society 125: 364-371.

Waldman, J.R., and I.I. Wirgin. 1998. Restoration options and prospects for Atlantic sturgeon Acipenser oxyrinchus in North America. Conservation Biology 12: 631-638.

Wirgin, I. 2012. Mixed stock analysis of adult and subadult Atlantic sturgeon from the Observers Program. Final Report submitted to NOAA's Office of Protected Resources, Gloucester, MA.

Wirgin, I., C. Grunwald, J. Stabile, and J. Waldman. 2007. Genetic evidence for mid-Atlantic coast relict Atlantic sturgeon stocks. North American Journal of Fisheries Management 27: 1214-1229.

Wirgin, I., L. Maceda, J.R. Waldman, S. Wehrell, M. Dadswell, and T. King. 2012. Stock origin of migratory Atlantic sturgeon in the Minas Basin, Inner Bay of Fundy, Canada, determined by microsatellite and mitochondrial DNA analyses. Transactions of the American Fisheries Society 141: 1389-1398.

Wirgin, I., J.R. Waldman, J. Rosko, R. Gross, M.R. Collins, S.G. Rogers, and J. Stabile. 2000. Genetic structure of Atlantic sturgeon populations based on mitochondrial DNA control region sequences. Transactions of the American Fisheries Society 129: 476-486.

Xu, S., C.J. Kobak, and P.E. Smouse. 1994. Constrained least squares estimation of mixed population stock composition from mtDNA haplotype frequency data. Canadian Journal of Fisheries and Aquatic Sciences 51: 417-425. 